Sartelli, S.L.. Los roles de género en cuentos infantiles: perspectivas no tradicionales. Derecho y Ciencias Sociales. Abril 2018. № 18. Pgs 199- 218. ISNN 1852-2971. Instituto de Cultura Jurídica y Maestría en Sociología Jurídica. FCJ y S. UNLP

\title{
Los roles de género en cuentos infantiles: perspectivas no tradicionales
}

Gender roles in children's short stories: non-traditional perspectives

Silvina Laura Sartelli

\section{Resumen}

Los roles tradicionales asignados a hombres y mujeres, en las esferas públicas y privadas, generalmente siguen un criterio binario sexista. Frente a esta visión se levantan otras posturas que proponen entender el género y el sexo como construcciones culturales. Estas tendencias también tienen su correlato en la literatura infantil y diversas investigaciones académicas han estudiado el impacto de estos textos sobre niños escolarizados.

Sobre la base de estos antecedentes, para este trabajo se seleccionaron cuentos infantiles en inglés y español que presentan novedosas perspectivas en materia de género. Los aportes teóricos de Bourdieu, De Beauvoir y Butler son incorporados al análisis de los mismos.

Palabras claves: Literatura infantil; género; roles

\begin{abstract}
The traditional roles assigned to men and women in domestic and public spheres generally follow a binary sexist pattern. By contrast, other points of view understand gender and sex as cultural constructions. These trends are also found in children literature and diverse academic researchers have studied the impact of these texts on schooled children.

For this paper, children's short stories, in both English and Spanish, have been selected to show the new perspectives in gender. The theoretical contributions provided by Bourdieu, De Beauvoir as well as Butler are incorporated to their analysis.
\end{abstract}

Keywords: Children literature; gender; roles

\footnotetext{
- Abogada (UNLP). Especialista en políticas de integración (IIL - UNLP). Magister en Integración Latinoamericana (IIL - UNLP). Ha realizado estudios sobre Literaturas Comparadas (Fahce -UNLP). Ex becaria FEP (Canadá) y Erasmus Mundus (España). Becaria Secretaría de Ciencia y Técnica, UNLP. Correo electrónico: slsartelli@hotmail.com
}

Recibido: 18/7/2017 Aceptado con correcciones: 28/12/2017 
Sartelli, S.L.. Los roles de género en cuentos infantiles: perspectivas no tradicionales. Derecho y Ciencias Sociales. Abril 2018. № 18. Pgs 199- 218. ISNN 1852-2971. Instituto de Cultura Jurídica y Maestría en Sociología Jurídica. FCJ y S. UNLP

\section{Los roles de género en cuentos infantiles: perspectivas no tradicionales}

\section{Silvina Laura Sartelli}

El aprendizaje no es sólo un proceso cognitivo sino, fundamentalmente, somático, en el que la opresión deja sus rastros no solamente en la mente de las personas sino también en sus músculos y en sus huesos (McLaren, 1993).

\section{Introducción}

La teoría feminista del siglo XX afirma la existencia de dos sexos, que se centran en las peculiaridades del sujeto femenino y masculino, respectivamente. Si bien se sostiene que el sexo es un hecho biológico, al ser vivido culturalmente -el cuerpo es el locus de las experiencias vividas- es difícil sostener la relación sexo/género-naturaleza/cultura (Femenías, 2001).

Frente a ello, las ideas superadoras de los conceptos de sexo y género, en cambio, suponen una suerte de modelo donde ya estamos construidos de una manera determinada. Así se habla cuerpos construidos culturalmente. Es decir, no hay posibilidad de un sexo natural, pues cualquier acercamiento teórico, conceptual, cotidiano o trivial al sexo se hace a través de la cultura y de su lengua. Al describir o al conceptualizar el sexo, lo hacemos desde unos parámetros culturales determinados, lo que lleva a Butler a entender que no es posible distinguir sexo y género. Ella utiliza de manera alternativa ambos términos como si fuera un continuo, para dar cuenta de que ya los cuerpos están culturalmente construidos y de allí que proponga la destrucción de la binariedad de géneros -la heterosexualidad normativamediante la proliferación de géneros (López Pardina, 2012).

Por otra parte, el disciplinamiento de $\operatorname{los}$ cuerpos $^{1}$ parte de la idea que "la cultura, históricamente, ha constituido a varones y a mujeres, probablemente a los fines de la procreación, como sujetos que desean lo que no son por definición también cultural” y bajo la lógica heterosexual, la cultura construye a las mujeres como deseantes de varones y a la inversa (Femenías, 2003: s/p).

La lógica heterosexual conlleva también roles que, culturalmente, se le asignan al hombre y a la mujer. De una u otra forma aquellos vienen a reforzarse por medio de prácticas sociales

\footnotetext{
${ }^{1}$ En este punto Butler sigue la idea del disciplinamiento compulsivo de Adrianne Rich. Butler entiende que el disciplinamiento de los cuerpos es uno de los tantos que sufrimos en nuestras vidas como humanos.
} 
Sartelli, S.L.. Los roles de género en cuentos infantiles: perspectivas no tradicionales. Derecho y Ciencias Sociales. Abril 2018. № 18. Pgs 199- 218. ISNN 1852-2971. Instituto de Cultura Jurídica y Maestría en Sociología Jurídica. FCJ y S. UNLP

diversas, y también son representados en los textos literarios. En efecto, la discriminación por sexo comúnmente es trasmitida a través de los cuentos y novelas donde se observan personajes arquetípicos y en los que los papeles, funciones y aspiraciones están perfectamente repartidos como forma de reproducción de la sociedad (Ocho, Parra y García, 2006).

La literatura infantil no escapa a este fenómeno. Los cuentos con final feliz, donde se asocia la consagración femenina con el matrimonio, el éxito con el poder, la fuerza con el mundo masculino y la sumisión con la femineidad, marcaron la educación de generaciones de niños. Si bien este tipo de textos aún sigue vigente en el mercado editorial, se avizora un nuevo rumbo en el que los estereotipos de género son revisados y donde nuevas identidades tienen un espacio.

En base a estas consideraciones, el propósito de este trabajo consiste en analizar cuentos infantiles, en inglés y español, que innovan en materia de género. Así, se observa qué aspectos coinciden con una lectura más tradicional de sus personajes principales y de qué forma se propone una superación de los estereotipos asignados a ambos sexos. Partiendo de la importancia que los textos tienen para la formación de los esquemas mentales de los niños, se estima de utilidad abordar aquella literatura que de alguna manera les ofrece una visión más totalizadora respecto de los roles de hombres y mujeres. Asimismo, se trabaja con los aportes teóricos proporcionados por Bourdieu, De Beauvoir y Butler.

\section{El género en la literatura infantil}

Entre los factores que se asocian al desarrollo de los estereotipos de género entre los niños, los libros ocupan un lugar trascendental. Es que además de enseñar sobre valores como la moral y la amistad, los textos también ayudan a la comprensión de los roles de hombres y mujeres en la sociedad, por medio del refuerzo de las ideas que ya tienen preconcebidas acerca de qué se considera típicamente apropiado para hombres y mujeres. Pero también los textos pueden desafiar esos mismos estereotipos.

La relación entre la literatura infantil y las cuestiones de género ha sido objeto de estudio en diversas oportunidades y con distintos enfoques. Algunas investigaciones se enfocaron en las ilustraciones que estos libros contienen para así determinar si había una mayor cantidad de personajes principales masculinos por sobre los femeninos. En otros casos, se propuso analizar el impacto de la exposición de los niños tanto a historias con roles y personajes estereotipados, como a relatos donde se muestran roles y personajes más igualitarios. Si 
Sartelli, S.L.. Los roles de género en cuentos infantiles: perspectivas no tradicionales. Derecho y Ciencias Sociales. Abril 2018. № 18. Pgs 199- 218. ISNN 1852-2971. Instituto de Cultura Jurídica y Maestría en Sociología Jurídica. FCJ y S. UNLP

bien en el primer caso se demostró un refuerzo de las ideas preconcebidas de los niños sobre las cuestiones de género, en el segundo supuesto los estereotipos sufrieron una disminución (Barclay, 1974; Berg-Cross \& Berg-Cross, 1978).

Sin ánimo de desmerecer estas conquistas, las investigadoras Diekman y Murnen (2004) realizaron otro estudio para determinar si los libros no-sexistas presentan equidad en los ámbitos típicamente masculinos y femeninos, partiendo de la idea de que se observa en la sociedad un aumento de las características masculinas adoptadas por mujeres, sin idéntica contrapartida por parte del mundo masculino. Esta asimetría en los cambios de roles y caracterizaciones sirvió de base a sus investigaciones y entre sus resultados se comprobó que los libros no sexistas eran únicamente más igualitarios en la representación de las características de la personalidad masculina, en tanto que se mantuvo la igualación en la medición de los aspectos femeninos ${ }^{2}$.

Pues bien, uno de los aspectos que generalmente se incluyen dentro del sexismo es el atinente al juego y actividades de diversión. En este punto se demostró que los niños prefieren jugar con juguetes típicamente asociados con su propio sexo, aún antes de los tres años (O'Brien y Huston, 1985). Sin embargo, también se comprobó que los libros sobre género atípico (gender-atypical storybooks) como ser aquellos que muestran a sus personajes en conductas propias del sexo opuesto, pueden conducir a cambios en la conducta de los chicos, aún en aquellos que presentan una conducta de juego más estereotipada que el resto de sus compañeros (Ashton, 1983; Green et al., 2004).

Asimismo, se comprobó que aquellos chicos en edad preescolar que fueron expuestos por un período de cuatro meses a textos en los que los personajes interactuaban con juguetes atípicos demostraron cambios significantes y estables en su comportamiento lúdico, con claras intenciones de adoptar juegos no estereotipados para su sexo por sobre aquellos que sí lo son. Por consiguiente, puede entenderse que la exposición de los personajes atípicos podría impactar en el comportamiento inmediato y futuro de los chicos.

Otra de las manifestaciones del sexismo y que aparece en varios de los textos sobre los que me referiré más abajo, es el relacionado con las ocupaciones de hombres y mujeres. Cuando los chicos son consultados sobre sus futuros trabajos, tienden a elegir aquellos rubros que

\footnotetext{
${ }^{2}$ Las investigadoras trabajaron con novelas reconocidas y/o premiadas de nivel elemental medio. Para la evaluación de la personalidad masculinidad se incluyeron, entre otros, estos aspectos (aun cuando la pregunta involucrara al personaje femenino): independencia, deseo de tomar riesgos, personajes dominantes, agresivos o con fuertes personalidades, liderazgo. La personalidad femenina incluyó: afección, sensibilidad, compasión, calidez, amabilidad, comprensión, Diekman y Murnen - Appendix: aspects of sexism in children's literature questionnaire, 2004: 382).
} 
Sartelli, S.L.. Los roles de género en cuentos infantiles: perspectivas no tradicionales. Derecho y Ciencias Sociales. Abril 2018. № 18. Pgs 199- 218. ISNN 1852-2971. Instituto de Cultura Jurídica y Maestría en Sociología Jurídica. FCJ y S. UNLP

están estereotípicamente asociados a su género (Liben et al., 2000). A modo de ejemplo, en una consulta realizada a varones de la escuela primaria sobre 37 ocupaciones, los estudiantes varones manifestaron su interés en aquellos que culturalmente se asocian a la masculinidad (profesorado, mecánico), situación que también se dio con las nenas encuestadas (gimnastas, maestras). En la investigación de Diekman y Murnen antes citada se observó que los roles ocupacionales fueron los que demostraron mayor división del trabajo de modo tradicional, seguidos de los roles domésticos y las actividades recreativas. Por otra parte, en materia de roles domésticos Karniol y Gal-Disegni (2009) descubrieron que aquellos alumnos de primer grado que trabajaron con textos más equitativos en cuanto a género, manifestaron que algunas actividades como jugar en el barro u hornear una torta eran apropiadas tanto para nenas como para nenes. Esta apertura no fue tan notoria en el grupo que trabajó con textos estereotipados, en los que generalmente se fija una línea más estricta respecto de los objetos asociados a unos y a otros.

Por último, la idealización de los tradicionales roles femeninos se ve reforzada por un sexismo benevolente que describe a la mujer desde una visión romántica, como seres delicados que requieren protección (Glick \& Fiske, 1996). El respaldo de este sexismo por parte de las propias mujeres lleva, por ejemplo, a la elección de parejas mayores, con mayor potencial de ingresos económicos (Johannesen-Schmidt y Eagly 2002, citado en Diekman y Murnen, 2004). Si bien podría pensarse que el ideal tradicional femenino que conlleva a una perpetuación de la inequidad de género existe tanto en los textos sexistas como en los que no lo $_{\text {son }}{ }^{3}$, lo valorable de los textos aquí analizados recae en que definitivamente rompen con este esquema.

Las descripciones y situaciones que se mencionan en los párrafos anteriores, concuerdan con lo que Judith Butler denomina la matriz heterosexual, productora de cuerpos y géneros hétero. Bajo esta matriz se observan modos de crianza occidentales en las cuales desde que nace un niño o una niña, cada uno tiene un lugar y un papel determinado en el mundo. De esta forma, si nace un varón "su ropa será azul, sus juegos estarán relacionados con la fuerza, la competencia y el poder (armas, carros, fútbol, caballos de madera etc.); tendrá menos restricciones en su movimiento (no usará vestidos largos e incómodos, faldas ni sandalias que por ejemplo le impidan subir a un árbol), el trato de los hombres de la casa

\footnotetext{
${ }^{3}$ Ello porque, tal como afirman Diekman y Murnen, a pesar de que en muchos textos considerados atíícos los personajes femeninos adoptan una postura de independencia y decisión, terminan por encasillarse en roles más tradicionales. Como ejemplo citan a Mujercitas de Louisa Mary Alcott. Es de remarcar que, contrariamente a lo esperado, en sus estudios las autoras descubrieron que este aspecto del sexismo es más pronunciado en los libros sexistas.
} 
Sartelli, S.L.. Los roles de género en cuentos infantiles: perspectivas no tradicionales. Derecho y Ciencias Sociales. Abril 2018. № 18. Pgs 199- 218. ISNN 1852-2971. Instituto de Cultura Jurídica y Maestría en Sociología Jurídica. FCJ y S. UNLP

hacia él tendrá cierto nivel de fuerza y temple; y por supuesto se le prohibirá en lo posible llorar ('los hombres no lloran') o ser 'afeminado' (maquillarse, jugar con muñecas o con utensilios de cocina), así como expresar atracción o sentimiento estético por otros niños" (Duque Costa, 2010, p. 29).

De allí que, frente a textos infantiles que aun proclamándose no sexistas solo demuestran una visión estrecha de la igualdad de género o que solo describen personajes femeninos que adoptan características y roles identificados con el género masculino, sin hacer lo propio con los personajes masculinos, aparece un grupo de historias que intentan superar algunas de estas limitaciones en pro de una mayor equidad.

\section{Nuevas perspectivas literarias}

Los cuentos que han sido seleccionados para este trabajo ${ }^{4}$ pertenecen a una literatura infantil que pretende desafiar los estereotipos propios de género. Por lo tanto, sus personajes adoptan conductas que no son comparables -ni esperables- con las típicas que se desprenden de la mayoría de los cuentos para niños. En términos de Butler (1993), estas historias pretenden romper la matriz heterosexual, o sea el conjunto de discursos y prácticas culturales relacionados con la diferenciación entre los sexos, y encaminados a producir la heterosexualidad. Vale aclarar, sin embargo, que generalmente las historias parten de situaciones estereotipadas para, a partir de allí, mostrar el quiebre conductual.

A los fines de analizar los textos, se optó por escoger cuatro aspectos en los que claramente se observa la diferenciación de las historias respecto de los libros más tradicionales. Ellos son los trabajos y ocupaciones, las características deseables, el matrimonio y la elección sexual.

\section{1.- Trabajo/ocupaciones}

El tema de las ocupaciones sexistas es abordado por el cuento Ballerino Nate. En él se propone trabajar sobre los estereotipos a través de un personaje principal (perro) que visiblemente se interesa más por la danza clásica que por otro tipo de juegos que socialmente se estiman más propios de un nene. Luego de asistir a una función de ballet con sus compañeros de jardín, Nate queda maravillado con los trajes y las piruetas de los

\footnotetext{
${ }^{4}$ En el Anexo se encuentra un resumen de los cuentos para un mejor seguimiento de sus análisis, así como otros datos de interés.
} 
Sartelli, S.L.. Los roles de género en cuentos infantiles: perspectivas no tradicionales. Derecho y Ciencias Sociales. Abril 2018. No 18. Pgs 199- 218. ISNN 1852-2971. Instituto de Cultura Jurídica y Maestría en Sociología Jurídica. FCJ y S. UNLP

bailarines. Su intención de aprender danza es muy criticada por su hermano, Ben, más proclive a los deportes. Durante el texto, Ben le reitera a su hermano que él no puede ser un bailarín porque es un niño: "You can't... You're a boy”... "Boys can't be dancers" ("No podés... Sos un chico”... “Los chicos no pueden ser bailarines”). La actitud propia del hermano es asociar el baile con un pasatiempo típicamente femenino para el cual se requiere usar zapatos y trajes de color rosa. Pero se destaca la actitud de la madre quien se muestra molesta por la insensibilidad de su hijo mayor. Al contrario, ella apoya a Nate, lo inscribe en una escuela de danza y lo lleva a ver un ballet para demostrarle que también los hombres pueden trabajar profesionalmente en esta actividad.

El aspecto positivo de la obra recae en la perseverancia del personaje quien a pesar de las presiones de su hermano y de descubrir que en las clases de danza sus compañeras son mujeres, la pasión y determinación lo llevan a concretar su sueño por sobre las presiones sociales y familiares.

Asimismo, se observa que este texto intenta superar la limitación a la que se hizo referencia anteriormente, en el sentido de que la mayoría de los textos calificados de no-sexistas muestran a los personajes femeninos en actitudes o roles típicamente masculinos, pero en escasas oportunidades se presenta el lado inverso. Pues bien, esta historia significa un paso adelante en ese punto.

En la misma línea The Princess Knight rompe con el estereotipo laboral. Violetta, su personaje principal, logra demostrar que puede realizar, con la misma o mayor maestría que sus hermanos, una actividad del dominio masculino (la caballería).

Tradicionalmente, aprender a tocar un instrumento, tomar clases de costura, bordado y telar, así como el baile son actividades que encuadran en el mundo femenino. Al respecto, Bourdieu (1998) manifiesta que

no es que las necesidades de la reproducción biológica determinen la organización simbólica de la división sexual del trabajo y, progresivamente, de todo el orden natural y social, más bien es una construcción social arbitraria de lo biológico, y en especial del cuerpo, masculino y femenino, de sus costumbres y de sus funciones, en particular de la reproducción biológica, que proporciona un fundamento aparentemente natural a la visión androcéntrica de la división de la actividad sexual y de la división sexual del trabajo (p. 37).

Las divisiones que plantea el autor, que se presentan como relaciones sociales de dominación y explotación, conducen a una clasificación de las cosas y prácticas reducible a 
Sartelli, S.L.. Los roles de género en cuentos infantiles: perspectivas no tradicionales. Derecho y Ciencias Sociales. Abril 2018. № 18. Pgs 199- 218. ISNN 1852-2971. Instituto de Cultura Jurídica y Maestría en Sociología Jurídica. FCJ y S. UNLP

lo que se considera femenino y masculino. Por ende, dentro del mundo femenino recaen las tareas domésticas y todos aquellos trabajos que impliquen escasa visibilidad y que responden a un mundo interior ${ }^{5}$, mientras que a los hombres se les asignan los actos peligrosos (entre los que podrían incluirse la caballería) o que implican una "ruptura en el curso normal de la vida", propios de la vida exterior y de trascendencia. Nótese aquí que la mujer que se encuentra al cuidado de Violetta la incentiva a realizar una actividad más pasiva, con lo que se reproduce la división antes expuesta: "What not to ask your father to stop teaching you all this silly fighting and let you learn something else instead? Embroidery perhaps. Or weaving. Or playing the flute. Something useful "," (Por qué no le pedís a tu padre que deje de enseñarte todas esas peleas tontas y deja en cambio que aprendás algo más? Bordado, tal vez. O telar. O tocar la flauta. Algo útil).

Lo importante de este esquema de pensamiento radica en el basamento de las propiedades negativas que se inculcan a las mujeres: su naturaleza, y es la relación de dominación la que consigue imponer y mantener esas cualidades. De esta manera la visión androcéntrica se legitima por las mismas prácticas que determina y el prejuicio desfavorable contra lo femenino termina siendo confirmado por las propias mujeres. Es que los propios dominados aplican a las relaciones de dominación categorías que fueron construidas tomando como referencia el punto de vista de los dominadores, con lo cual aparecen como naturales. Es que la violencia simbólica crea la obligación para el dominado de adherir al dominador por no tener la capacidad de entender su relación de otra forma distinta a la pensada por aquél, de allí que se naturalice (Bourdieu, 1998).

La naturalización de la que habla Bourdieu se observa en varios de los textos bajo análisis. Es muy clara la descripción de esta situación en Arturo y Clementina, historia donde el personaje femenino (dominado) entiende que los dichos de Arturo (dominador) sobre sus cualidades (negativas: distracción, ingratitud, tontera) son los correctos. Esa percepción por parte de Clementina sobre sí misma ratifica las categorías que son construidas bajo el modelo del dominador. De este modo, los actos de conocimiento y reconocimiento del poder simbólico pueden adoptar la forma de emociones corporales (vergüenza, culpabilidad, timidez), pasiones y sentimientos (respeto). Estas emociones no son sino maneras de

\footnotetext{
${ }^{5}$ Aclara Bourdieu que las tareas exteriores que se les asignan son "las relacionadas con el agua, con la hierba, con lo verde (como la escardadura y la jardinería), con la leche, con la madera, y muy especialmente los más sucios, los más monótonos y los más humildes" (p. 45).

${ }^{6}$ Resaltado en el original.
} 
Sartelli, S.L.. Los roles de género en cuentos infantiles: perspectivas no tradicionales. Derecho y Ciencias Sociales. Abril 2018. № 18. Pgs 199- 218. ISNN 1852-2971. Instituto de Cultura Jurídica y Maestría en Sociología Jurídica. FCJ y S. UNLP

someterse a la opinión dominante, aunque lo sea de forma no voluntaria o hasta inconsciente.

Los diálogos transcriptos a continuación reflejan estos conceptos:

A: ¡Sólo se aburren los tontos! A Clementina le daba mucha vergüenza ser tonta...

A: ¡Tú! ¿Tocar la flauta, tú? ¡Si ni siquiera distingues las notas! Eres incapaz de aprender. No tienes oído. Y aquella misma noche, Arturo llegó con un hermoso tocadiscos, y lo ató bien a la casa de Clementina, mientras le decía: Así no lo perderás. ¡Eres tan distraída!

C: ...si era verdad que no hubiera llegado a aprender las notas y que era distraída. Pero después, avergonzada, decidió que tenía que ser así, puesto que Arturo, tan inteligente, lo decía. Suspiró resignada y se durmió.

A: ¡Vaya idea ridícula! ¿Es que te crees una artista? ¡Qué bobada!

C: Vaya, ya he vuelto a decir una tontería. Tendré que andar con mucho cuidado o Arturo va a cansarse de tener una mujer tan estúpida.
A: ¿Qué harías tú sin mí?
C: Claro. ¿Qué haría yo sin ti?

Este tipo de descripciones y diálogos nos ilustran de qué forma la propia mujer reconoce su inferioridad frente a la dominación del mundo masculino con una clara incapacidad de definirse como un sujeto distinto, como ente no pasivo, con resignación ${ }^{7}$.

Las cuestiones y planteamientos que se suscitan en torno a los mandatos y expectativas atribuidas a uno y otro género llevan a Butler a replantearse la relación sexo-género ${ }^{8}$. La autora entiende que la sociedad tiene previstos culturalmente un número de mandatos, de funciones que son asignados a los sexos de manera tal que esas funciones, esos mandatos, esa construcción social generan las distinciones, las divisiones y las características que nosotros llamamos "naturales". Sin embargo, no hay posibilidad de un acceso a "lo natural" como si fuera algo "originario" e "independiente de concepciones culturales" de esto que damos en llamar "naturaleza". Sólo es posible acceder a lo natural desde lo cultural, no hay forma alguna de colocarnos en algún lugar desde donde lo cultural no intervenga para

\footnotetext{
7 “... el Universo, en su conjunto, es masculino; han sido los hombres quienes le han dado forma, lo han regido y todavía hoy lo dominan; en cuanto a ella, no se considera responsable de nada de eso; se sobreentiende que es inferior, dependiente; no ha aprendido las lecciones de la violencia, jamás ha emergido como un sujeto ante otros miembros de la colectividad; encerrada en su carne, en su morada, se capta como ente pasivo frente a esos dioses con rostro humano que definen fines y valores..." (De Beauvoir, 1972, p. 338).

${ }^{8}$ Se recuerda que Butler usa indistintamente los términos sexo y género.
} 
Sartelli, S.L.. Los roles de género en cuentos infantiles: perspectivas no tradicionales. Derecho y Ciencias Sociales. Abril 2018. № 18. Pgs 199- 218. ISNN 1852-2971. Instituto de Cultura Jurídica y Maestría en Sociología Jurídica. FCJ y S. UNLP

acceder a lo biológico. Es decir, lo único que tenemos como "dato" es lo "culturalmente" entendido como biológico o como natural.

En último lugar, para concluir este apartado relativo a las ocupaciones y a la influencia que la lectura de textos no tradicionales puede tener sobre los niños, quisiera incluir la conclusión de una investigación realizada por Nhundu's (2007). Durante el trabajo realizado con niñas de entre 4 y 7 grado, se observó que la lectura de libros no atípicos puede alterar las aspiraciones y objetivos laborales. Las niñas que tomaron conocimiento de textos biográficos de mujeres exitosas en carreras no tradicionales no solo manifestaron que no había trabajos que únicamente puedan ser realizados por uno u otro sexo, sino que también han llegado a cambiar sus propios planes laborales escogiendo uno atípico para mujeres.

\section{2.- Características o cualidades deseables}

Lo que es esperable de una mujer en cuanto su imagen, modo de conducirse y modales es otro aspecto que se incluye en muchos de los textos analizados. Dentro del "carácter" de la mujer se incluyen muchas cualidades negativas como la mezquindad, la inexactitud, inmoralidad o el sentido de la contradicción (De Beauvoir, 1972), pero al igual que no existe una predisposición natural para realizar uno u otro trabajo, tampoco estas actitudes "son dictadas a la mujer por sus hormonas, ni están prefiguradas en los compartimientos de su cerebro: están indicadas por su situación” (338). Por eso, según el pensamiento de la autora francesa, el “'eterno femenino’ es una construcción del mundo masculino que las heterodesigna como lo Otro en una relación que ni es recíproca ni simétrica con los varones" (Femenías, 2001, p. 76).

En el cuento Rosa Caramelo se observa claramente cómo el personaje se esmera, sin lograrlo, por alcanzar el color rosa que toda elefanta debiera tener para ser bella. Se asocia el sexo femenino con un determinado color (rosa) y con ciertas características que obligan, incluso, a su personaje a esforzarse por alcanzarlos:

“...una manada en que las elefantas eran suaves como el terciopelo, tenían los ojos grandes y brillantes, y la piel de color rosa caramelo...", "Y no era que les gustaran estas flores: las anémonas- y todavía peor las peonias- tienen un sabor malísimo. Pero eso sí, dan una piel suave y rosada y unos ojos grandes y brillantes...”, “...Para volverse más rosas, las elefantitas llevaban zapatitos color de rosa, cuellos color de rosa y grandes lazos color de rosa en la punta del rabo...". 
Sartelli, S.L.. Los roles de género en cuentos infantiles: perspectivas no tradicionales. Derecho y Ciencias Sociales. Abril 2018. № 18. Pgs 199- 218. ISNN 1852-2971. Instituto de Cultura Jurídica y Maestría en Sociología Jurídica. FCJ y S. UNLP

Incluso se cuestiona por parte del padre de Margarita los magros resultados que alcanza su hija:

¿Por qué sigues con ese horrible color gris, que sienta tan mal a una elefantita? ¿Es que no te esfuerzas? ¿Es que eres una niña rebelde? ¡Mucho cuidado, Margarita, porque si sigues así no llegarás a ser nunca una hermosa elefanta!

Esto contrasta con la forma en que se muestra a los personajes masculinos, dado que a ellos no se les niega la capacidad de disfrute a través del juego, así como tampoco la posibilidad de realizar actividades que los personajes femeninos tienen vedados (ensuciarse y divertirse en el barro). Precisamente, es contra estas limitaciones y privaciones que Margarita y el resto de las elefantas se revelan.

Ahora bien, la literatura sobre género también aborda el estudio de los parámetros estéticos y conductuales. Al respecto se sostiene que el comportamiento y la forma de mantener el cuerpo obedecen a la naturalización de una ética (Bourdieu, 1998). Como prueba de ello, la sumisión femenina se constata en el hecho de inclinar o doblar el cuerpo, de someterse, de las posiciones curvas e incluso de pensar que la docilidad es más adecuada para la mujer que para el hombre?

En el otro cuento de Alicia Turín, Arturo y Clementina nuevamente surge la caracterización del sexo femenino como aburrido y pasivo, incluso se describe cómo es visto desde el punto de su pareja quien tiende a desmerecer su capacidad:

... ¡Me he aburrido mucho! ¡Todo el día esperándote! -¡Aburrido!-gritaba Arturo indignado. ¿Dices que te has aburrido? Busca algo que hacer. El mundo está lleno de ocupaciones interesantes. ¡Sólo se aburren los tontos!...

... A Clementina le daba mucha vergüenza ser tonta, y hubiera querido no aburrirse tanto, pero no podía evitarlo....

...¡Tú! ¿Tocar la flauta, tú? ¡Si ni siquiera distingues las notas! Eres incapaz de aprender. No tienes oído. Y aquella misma noche, Arturo llegó con un hermoso tocadiscos, y lo ató bien a la casa de Clementina, mientras le decía: Así no lo perderás. ;Eres tan distraída!...

\footnotetext{
${ }^{9}$ Sobre este punto Bourdieu agrega que “...toda nuestra ética, por no mencionar nuestra estética, reside en el sistema de adjetivos cardinales, alto/bajo, recto/torcido, rígido/flexible, abierto/cerrado, etc., de los que una buena parte indica también unas posiciones o unas disposiciones del cuerpo, o de alguna de sus partes; por ejemplo, la «frente alta», la «cabeza baja»" (Bourdieu, 1998: 42).
} 
Sartelli, S.L.. Los roles de género en cuentos infantiles: perspectivas no tradicionales. Derecho y Ciencias Sociales. Abril 2018. № 18. Pgs 199- 218. ISNN 1852-2971. Instituto de Cultura Jurídica y Maestría en Sociología Jurídica. FCJ y S. UNLP

Como se observa claramente, ambos cuentos toman como punto de inicio la matriz heterosexual -a la que se hizo referencia en el punto II del presente trabajo- para luego presentar un quiebre en las caracterizaciones y elecciones de los personajes principales. Esa evolución consiste en el principal aporte de la afamada escritora italiana hacia una mayor igualdad.

No solo la mujer responde a un parámetro estético y conductual preestablecido. Al hombre también se le atribuyen ciertas características y modos de comportarse que derivan de la matriz heterosexual a la que ya se hizo referencia. Sobre este punto trabaja 10,000 dresses, primer cuento que presenta la experiencia de un personaje transgénero o, al menos, de género variante. Las reacciones de su familia son las esperables en una situación similar (negación de sus gustos e inclinaciones por su condición de varón, rechazo por parte de sus hermanos, a quienes se los ilustra en típicos juegos masculinos), pero lo interesante del cuento es la posibilidad que tiene Bailey de encontrar una amiga con quien mostrarse libremente tal cual es.

\section{3.- Matrimonio}

La institución matrimonial es un tema recurrente en los textos seleccionados. En algunos casos aparece como una exigencia impuesta por los progenitores del personaje, aunque eventualmente no llegue a concretarse.

Tal los casos de Rosa caramelo, donde el padre recrimina a Margarita su apagado color gris, impedimento para ser una hermosa elefanta y, posteriormente, contraer matrimonio. También se muestra este imperativo en The princess knight en el que el padre de Violetta encierra a su hija en una torre por negarse a casarse con el potencial ganador de la competencia. Aquí aparece una resistencia por parte del personaje principal al mandato social, quien incluso termina por casarse con alguien de su propia elección luego de modificar la exigencia de hacerlo con quien estaba preestablecido.

Simone de Beauvoir (1972) ya manifestaba que

el destino que la sociedad propone tradicionalmente a la mujer es el matrimonio. La mayor parte de las mujeres, todavía hoy, están casadas, lo han estado, se disponen a estarlo o sufren por no estarlo. La soltera se define con relación al matrimonio, ya sea una mujer frustrada, sublevada o incluso indiferente con respecto a esa institución (p. 205). 
Sartelli, S.L.. Los roles de género en cuentos infantiles: perspectivas no tradicionales. Derecho y Ciencias Sociales. Abril 2018. № 18. Pgs 199- 218. ISNN 1852-2971. Instituto de Cultura Jurídica y Maestría en Sociología Jurídica. FCJ y S. UNLP

Si bien con el correr del tiempo la mirada de la mujer -y de la sociedad- frente al matrimonio ha sido suavizada ${ }^{10}$, no puede desconocerse la importancia que esta institución ha tenido como práctica o mandato para la mujer.

La vivencia del matrimonio también se presenta en La princesa que no quería comer perdices con la particularidad de que aquí se muestra cómo es la vida del personaje principal junto a quien, en el imaginario social, asoma como la pareja ideal. Se describe la realidad por la que atraviesa Cenicienta, que lejos está de ser lo que ella esperaba en su vida de casada. Vive una cotidianeidad marcada por el descrédito, los insultos, la violencia verbal $^{11}$.

Incluso, los comentarios que provienen de algunos personajes secundarios refuerzan ese ideal: "No te quejes. ¿Dónde vas a estar mejor que con un príncipe?”.

El punto distintivo del cuento radica en romper con la arbitraria asociación de la felicidad a través del matrimonio y plantear un mensaje revitalizador para la mujer. La propia princesa reconoce su inocencia al pensar que "un príncipe la salvaría", como tampoco lo haría "un camionero" o "un disc-jockey" pues la salvación pasa por una misma.

La situación que lleva al personaje de este cuento a tomar esa decisión es similar a la descrita en Arturo y Clementina. En ambos textos aparecen el malestar, la decepción, el maltrato verbal y una vida que no cumple las expectativas de sus personajes. Tanto Clementina como Cenicienta deciden poner fin a esas ataduras.

\section{4.- Elección sexual}

En estrecha relación con el punto anterior, algunos textos infantiles abordan el tema de la libertad de elección sexual. Ante la idea que afirma que, por razones culturales y bajo la lógica heterosexual, las mujeres necesariamente aparecen como deseantes a los varones y viceversa (Femenías, 2003), se encuentra aquella que pregona la libertad en la elección

\footnotetext{
10 Tal es así que la figura del divorcio conyugal fue incorporada al régimen civil, algo impensado jurídicamente algunas décadas atrás.

11 "El matrimonio alienta al hombre hacia un caprichoso imperialismo: la tentación de dominar es la más universal, la más irresistible de todas las tentaciones [...] entregar el hijo a la madre, entregar la mujer al marido, es cultivar en la tierra la tiranía; con frecuencia, no le basta al esposo ser aprobado y admirado, aconsejar y guiar; ordena, juega al soberano; de todos los rencores acumulados durante su infancia, a lo largo de toda su vida, cotidianamente amasados entre los otros hombres cuya existencia le veja y le molesta, se libra en su casa asestando su autoridad contra su mujer; imita la violencia, el poder, la intransigencia; emite órdenes con tono severo, o bien grita, golpea la mesa: esta comedia es para la mujer una cotidiana realidad" (De Beauvoir, 1972, p. 247).
} 
Sartelli, S.L.. Los roles de género en cuentos infantiles: perspectivas no tradicionales. Derecho y Ciencias Sociales. Abril 2018. № 18. Pgs 199- 218. ISNN 1852-2971. Instituto de Cultura Jurídica y Maestría en Sociología Jurídica. FCJ y S. UNLP

sexual de las personas y sobre esta cuestión también existen textos infantiles que ilustran estas realidades sociales.

Entre la oferta extranjera se encuentra el texto de María Luisa Guerrero, titulado La princesa Ana. Considerado el primer cuento sobre relaciones lésbicas, el relato cuenta la historia de una princesa a quien, por imperativo cultural, su padre quiere casar con un príncipe.

Ana desde muy pequeña inicia una relación con una rana a quien le confiesa sus verdaderos sentimientos. Finalmente, la rana convertida en mujer contrae matrimonio con Ana. Es novedosa la utilización que la autora hace de la clásica conversión de rana en príncipe a través de un beso -algo típico de muchos cuentos tradicionales- para implementar la transformación del animal en una mujer.

El cuento -que ha recibido varios galardones ${ }^{12}$ - resulta una gran contribución a la libre elección sexual, con la consecuente posibilidad legal de la existencia de parejas de un mismo sexo. Nótese que sobre el final del texto se deja entreabierta la puerta a un cambio en el régimen hasta entonces impuesto en el reinado. Esta decisión encuentra cierto paralelismo al cambio legal que se ha dado en España -lugar de edición del libro- con la implementación del matrimonio entre personas del mismo sexo en $2005^{13}$.

De modo similar, el cuento Mommy, mama and me trabaja sobre la constitución de familias homoparentales. En el texto se describen las actividades que un niño comparte diariamente con sus dos mamás -como la preparación del desayuno, la recreación, los preparativos para la escuela-tareas que, en un modelo heteronormativo, son distribuidas entre madre y padre. Una versión similar de este cuento se ha publicado para el caso de parejas homosexuales masculinas bajo el título Daddy, papa and me. Destaca en ambos textos la rítmica como recurso retórico efectivo.

Merece destacarse que el trabajo de esta autora sobre la constitución de las familias de un mismo sexo no es algo reciente. Ya en 1989 publicó su primer cuento sobre esta temática (Heather has two mommies ${ }^{14}$ ) el que se convirtió en un hito en la literatura infantil. En el

\footnotetext{
${ }^{12}$ Entre ellos el premio "Sal a escena contra la discriminación", concedido por el Ministerio de Sanidad, Política Social e Igualdad, Gobierno de España, 2010.

${ }^{13}$ La Ley 13/2005 fue sancionada por el Rey, Juan Carlos I, el día 1 de julio de 2005. Se publicó en el Boletín Oficial del Estado el día 2 de julio de 2005, y entró en vigor el día siguiente, 3 de julio de 2005. La Ley 13/2005 reforma el Código Civil en lo concerniente al derecho a contraer matrimonio. Puntualmente, esta reforma añade un segundo párrafo al vigente artículo 44 del Código civil en los siguientes términos: " $E l$ hombre y la mujer tienen derecho a contraer matrimonio conforme a las disposiciones de este Código. El matrimonio tendrá los mismos requisitos y efectos cuando ambos contrayentes sean del mismo o de diferente sexo".

${ }^{14}$ El libro ha sido traducido al español con el nombre de Paula tiene dos mamás, editorial Bellaterra, 2003.
} 
Sartelli, S.L.. Los roles de género en cuentos infantiles: perspectivas no tradicionales. Derecho y Ciencias Sociales. Abril 2018. № 18. Pgs 199- 218. ISNN 1852-2971. Instituto de Cultura Jurídica y Maestría en Sociología Jurídica. FCJ y S. UNLP

relato una niña con dos madres empieza a concurrir al jardín de infantes y allí advierte que su familia no es igual a la de la mayoría de los chicos. Ante esta realidad, la maestra le pide a cada uno de sus alumnos que dibujen a su propia familia para que tomaran conciencia de las múltiples formas en que una familia puede estar formada.

Al igual que el caso de Guerrero en español, el libro de Lesléa Newman fue pionero en abordar, en inglés, el tema de las familias homoparentales. La recepción inicial causó múltiples controversias ${ }^{15}$, pero sirvió para instalar el tema en la literatura infantil norteamericana.

En el plano nacional también existen cuentos, de edición reciente, en los que se trata de presentar a los lectores diversas formas de composición familiar. Entre los más salientes se encuentra Anita y sus dos mamás, que habla sobre la crianza en una familia de madres lesbianas. El auge de esta literatura se vio favorecida por la sanción de las leyes de matrimonio igualitario y de identidad sexual. Si bien ya existían algunas editoriales que publicaban textos sobre temática lésbica, gay, de transgénero y bisexual (LGTB) ${ }^{16}$ Molinos de Viento fue la primera dedicada exclusivamente al género en formato de papel.

\section{Conclusiones}

La literatura infantil es un factor de transmisión cultural utilizado principalmente durante la socialización primaria que permite inculcar valores diversos. También el cuento infantil puede ser una vía por la cual perpetuar la discriminación por sexo marcada por una cultura patriarcal en donde la mujer sumisa espera al héroe y a su príncipe, la madrastra siempre es mala y los niños son aventureros, malvados y violentos. Es que la influencia que la literatura ejerce determina que los niños creen pautas de conducta determinadas basadas en la información recibida, que serán a su vez perpetuadas durante su vida y trasmitidas, nuevamente, a una siguiente generación.

Frente a este escenario, los textos aquí presentados pretenden erradicar este tipo de discriminaciones, al presentar personajes que no necesariamente encajan en el sistema binario masculino/femenino, sobre el cual se formaron las categorías de género y sexo, o simplemente rompen con el paradigma heteronormativo. Desde este punto de vista, la

\footnotetext{
${ }^{15}$ La propia autora, en distintas entrevistas realizadas con motivo de la reedición del libro en 2016, recuerda las trabas que la publicación, y posterior recepción, tuvo Heather has two mommies, "Great Expectations: The Journey of Heather Has Two Mommies", The Huffington Post, 02/02/16. Disponible en https://www.huffingtonpost.com/leslea-newman/post_9206_b_6929784.html

${ }^{16}$ De modo digital, Bajo el arco iris publica textos para niños y jóvenes sobre temas LGBTI.
} 
Sartelli, S.L.. Los roles de género en cuentos infantiles: perspectivas no tradicionales. Derecho y Ciencias Sociales. Abril 2018. No 18. Pgs 199- 218. ISNN 1852-2971. Instituto de Cultura Jurídica y Maestría en Sociología Jurídica. FCJ y S. UNLP

literatura analizada implica un avance en la formación de los educandos, contribuyendo a reflexionar acerca de la importancia de fomentar la igualdad áulica.

En este sentido, debe tenerse en cuenta que Beauvoir afirmaba que el cuerpo es en parte cultura y en parte también es una elección, o sea que presenta la doble vertiente de proyecto y de constructo (cuerpo “en situación"). Pero el sexo es un dato que no se puede cuestionar (López Pardina, 2012; Femenías, 2010). Butler va más allá y señala que el locus de género mujer no necesariamente debe ser un cuerpo hembra, a diferencia de lo que pensaba Beauvoir ${ }^{17}$. La filósofa americana plantea que no solo el género sino que también el sexo responden a una significación cultural. Por ende, solo tenemos constructos culturales. Por otra parte, también se cuestiona si existe un sujeto anterior a sus acciones o si, como señala Butler, uno es las acciones que realiza. De allí que para ella sea tan importante la teoría de la performatividad.

Sumado a ello, los textos nos invitan a reflexionar sobre la concepción occidental del sexo como algo binario, exclusivo y excluyente -en términos de Femenías. Este sexismo también está presente en el lenguaje desde que no existe una terminología que permita referirse a una persona que no pueda encuadrarse en el mundo femenino/masculino. En este sentido, el cuento 10,000 dresses innova en la materia al referirse al personaje principal (masculino) con una persona y pronombre femeninos (she/her).

Asimismo, desde un punto de vista filosófico puede entenderse que los cuentos escogidos contribuyen al existencialismo -línea en la que se enrolaba Beauvoir- desde que intentan luchar contra las esencias, siempre prescriptivas, que determinan ciertas características en la mujer y en el varón.

Por otra parte, también se podría hacer un paralelismo con la idea del disciplinamiento del deseo $^{18}$, como modo de control y de dirección a la que los cuerpos son sometidos, o sea el deseo dirigido hacia aquello para lo cual hubo un mandato discursivo previo. Traspolando estas ideas a los textos trabajados puede decirse que los personajes, si bien inicialmente adoptan los mandatos que la sociedad les fija -bajo una lógica binaria- logran apartarse de los mismos y ver al deseo con un sentido positivo, es decir -como afirma Butler- el deseo como hacedor, constructivo de su propio objeto. No es un dato menor que el deseo ocupe un

\footnotetext{
${ }^{17}$ De esta manera, Butler critica a De Beauvior y entiende el "llegar a ser mujer" de la filósofa francesa como "un proceso activo de apropiación, de interpretación, y de reinterpretación, de auto-construcción de la identidad, y de adopción de un cierto estilo corporal, de un significado dado, asumido o encarnado propositivamente y construido a partir del lenguaje falogocéntrico". Se recuerda que Butler le atribuye a Beauvoir el concepto de género que la filósofa francesa nunca utilizó (Femenías, 2001, p. 74).

${ }^{18}$ Aspecto que Butler toma de Foucault.
} 
Sartelli, S.L.. Los roles de género en cuentos infantiles: perspectivas no tradicionales. Derecho y Ciencias Sociales. Abril 2018. № 18. Pgs 199- 218. ISNN 1852-2971. Instituto de Cultura Jurídica y Maestría en Sociología Jurídica. FCJ y S. UNLP

lugar en aquello que se transmite a los niños a través de la lectura. En este punto, los cuentos indicados en el apartado 4 (elección sexual) abren un espacio en la literatura infantil donde los personajes viven en familias homoparentales de igual forma que aquellos que lo hacen en las heterosexuales. Así, la formación de parejas que no encuadran en el paradigma heteronormativo -el cual elimina la posibilidad de pensar la orientación sexual como una elección- junto a la naturalización de ese hecho ${ }^{19}$, son los aspectos más salientes de cuentos escogidos.

En consecuencia, sea que se adopte una u otra postura teóricas -la feminista y modernista de Beauvoir o la postfeminista y postmodernista de Butler-, lo significativo radica en que esta novedosa literatura infantil demuestra que el sexo no condiciona el género, no limita las elecciones ni los roles que pueden ejercerse en la construcción de la vida, y muestran otra mirada acerca de lo que es ser mujer o varón. Nos invita a reflexionar sobre la construcción de nuevos significados sobre el cuerpo, incluyendo aquellas corporalidades que han sido sistemáticamente omitidas, sometidas y excluidas.

\section{Descripción de fuentes}

\section{Kimberly Brubaker Bradley (2006) Ballerino Nate. Dial Books}

Nate decide ser un bailarín clásico. A pesar de la presión de su hermano, Nate persiste en sus sueños y encuentra el acompañamiento necesario en sus padres. Asiste a clases de baile y se encuentra con que es el único chico, razón por la cual su hermano continúa riéndose de él. Finalmente, su madre lo lleva a un gran teatro a ver una obra de ballet, y es allí donde Nate ve que los hombres también pueden ser bailarines.

\section{Cornelia Funke (2004)The princess knight.}

Violetta es una princesa a quien su padre le enseña, al igual que sus hermanos, el arte de la caballería. De noche, Violetta entrena duramente para convertirse en la mejor protectora en su tierra. Su padre organiza un torneo para entregar la mano de Violetta a su ganador, a lo que ella se niega rotundamente. Así decide participar en el torneo usando un disfraz y al ganarlo proclama que elegirá libremente a su pareja. Finalmente se casa con el jardinero del palacio.

\section{Alicia Turín (1976) Arturo y Clementina. Lumen}

\footnotetext{
19 La heteronormatividad esencializa la sexualidad dado que la heterosexualidad sería una suerte de "naturaleza" y quienes no la respetan, aparecen como antinaturales, anormales, enfermas/os, etc. (Rich, 1985).
} 
Sartelli, S.L.. Los roles de género en cuentos infantiles: perspectivas no tradicionales. Derecho y Ciencias Sociales. Abril 2018. № 18. Pgs 199- 218. ISNN 1852-2971. Instituto de Cultura Jurídica y Maestría en Sociología Jurídica. FCJ y S. UNLP

Arturo y Clementina cuenta la historia de dos tortugas. Clementina tenía muchos sueños y gran parte de estos quiso entonces realizarlos junto a Arturo, en especial viajar y conocer el mundo. Una vez casados decidió que no era necesario que Clementina viajara a ningún lado, que con que se quedara en casa bastaba, que él saldría y la abastecería de todo lo que necesitara. Clementina no estaba conforme con su nueva vida, no quería quedarse en casa todo el día esperando a que llegara Arturo. Pensaba en usar su día en algún pasatiempo que le enriqueciera la vida como pintar o tocar la flauta. Pero Arturo no creía que ella fuera capaz de esas cosas, la encontraba tonta, aburrida y muy despistada. Cansada de acumular regalos decidió salirse del caparazón y caminar así, liviana y sin equipaje, recobrando de esta manera un poco de alegría y de su propia vida. Arturo no comprendía y miraba con sospecha el nuevo ánimo de su esposa. Pronto llegó el día en que Arturo volvió a su casa por la tarde y no encontró a Clementina por ningún lado.

\section{Alicia Turín ( 1976) Rosa caramelo. Lumen}

Margarita y otras pequeñas elefantas viven aisladas en un jardín de anémonas y peonías; su alimento para conseguir un aspecto físico caracterizado por el color rosa caramelo de su piel, que refuerzan luciendo zapatos, lazos y cuellos del mismo tono. Todas cumplen las expectativas de sus padres y madres excepto ella, que sufre los reproches de sus progenitores hasta que éstos desisten que sea como las demás. Margarita se une a sus compañeros y empieza a disfrutar de la vida como solo ellos lo hacían hasta entonces.

\section{Marcus Ewert (2008) 10,000 dresses. Seven stories press}

A Bailey le encantan los vestidos con los que sueña. Decirle contarles a sus padres sobre ellos aunque ninguno en su familia está interesado en sus sueños porque es un chico. Bailey conoce a Laurel hacia al final de la historia, una mujer que hace vestidos, quien acepta a Bailey y a sus sueños.

\section{Myriam Cameros Sierra, Nunila López Salamero ( 2009) La cenicienta que no quería comer perdices. Planeta}

La protagonista femenina principal de este cuento es Cenicienta. Una mujer que tras mucho intentarlo consigue ir al baile que ofrece el príncipe en su palacio, pero una vez que se casa con él descubre que la vida junto a un príncipe no era como ella se la imaginaba, que no es feliz, que se siente sola, reprimida y poco valorada; sus deseos no son tenidos en cuenta por su marido que la trata como si fuera una criada para él. La protagonista evoluciona a lo largo de la historia y tanto su carácter como su forma de ser y de relacionarse con los demás van evolucionando con ella, tras 
Sartelli, S.L.. Los roles de género en cuentos infantiles: perspectivas no tradicionales. Derecho y Ciencias Sociales. Abril 2018. No 18. Pgs 199- 218. ISNN 1852-2971. Instituto de Cultura Jurídica y Maestría en Sociología Jurídica. FCJ y S. UNLP

abandonar al príncipe y comprender que no necesita de nadie para ser feliz decide vivir su vida a su manera sin tener en cuenta lo que de ella se espera ni tratar de cumplir con las pautas establecidas.

María Luisa Guerrero ( 2009) La princesa Ana Ellas. Edición bilingüe español-inglés a cargo de la publicación de ONG por la No discriminación.

Ana era una princesa a quien no le faltaba nada. Siguiendo las costumbres, su madre comienza la búsqueda para hallar un príncipe con quien casarse pero a ella no le gustaba ninguno. A partir de este momento, Ana se fue volviendo cada vez más apagada y triste. Le confiesa cómo se siente a su mejor amiga, una rana y sus intenciones de casarse con ella. Luego de un beso la rana se convierte en princesa y termina casándose con Ana.

\section{Leslea Newman ( 2009) Mommy, mama and me. Tricycle Press}

Cuenta la historia de una niña que pasa sus días junto a sus dos mamás. Con ellas comparte los juegos, la hora del baño e incluso el beso de buenas noches. Muestra claramente el vínculo amoroso entre parejas del mismo sexo y sus hijos.

Lesléa Newman (1989) Heather has two mommies. In other words publishing

Heather tiene dos mamás: Jane y Kate, una su madre biológica, quien por medio de una inseminación le dio la vida. La otra mamá, es su pareja. Cuando Heather va a la escuela por primera vez alguien le pregunta por su papá. Como método para mostrar las variadas formas en que una familia puede estar constituida, la maestra les propone a sus alumnos dibujarlas. Los chicos así aprenden que no importa por quién está formada la familia sino el amor que sus miembros sienten entre ellos.

\section{Darío Fernández (2015) Anita y sus dos mamás. Molinos de viento}

Ana es una niña que comparte sus actividades diarias con sus dos mamás: Eva y Mimi, que está embarazada esperando el segundo hijo de esta familia. Con ambas comparte los juegos, diversiones, las tareas del colegio, las comidas. De forma naturalizada, se muestra la vida de una niña en edad escolar junto a una familia no tradicional.

\section{Bibliografía}

Ashton, E. (1983). Measures of play behavior: The influence of sex-role stereotyped children's books, Sex Roles, 9(1), 43-47.

Barclay, L. K. (1974). The emergence of vocational expectations in preschool children. Journal of Vocational Behavior, 4, 1-14.

Berg-Cross, L. y Berg-Cross, G. (1978). Listening to stories may change children's social attitudes. Reading Teacher, 31, 659-663. 
Sartelli, S.L.. Los roles de género en cuentos infantiles: perspectivas no tradicionales. Derecho y Ciencias Sociales. Abril 2018. № 18. Pgs 199- 218. ISNN 1852-2971. Instituto de Cultura Jurídica y Maestría en Sociología Jurídica. FCJ y S. UNLP

Bourdieu, P. (1998). La dominación masculina. Barcelona: Anagrama.

De Beauvior, S. (1972). El segundo sexo. Buenos Aires: Ediciones Siglo XX.

Diekman, A. B. y Murnen, S. K. (2004). Learning to Be Little Women and Little Men: The Inequitable Gender Equality of Nonsexist Children's Literature. Sex Roles, Volume 50(56), 373-385. Disponible en https://www.ncbi.nlm.nih.gov/pmc/articles/PMC3872116/. Fecha de consulta 15/02/17.

Duque Acosta, C. A. (2010). Judith Butler: performatividad de género y política democrática radical. La manzana de la discordia, enero - junio, 5(1), 27-34.

Femenías, M. L. (2001). Modelizaciones en torno al problema de la construcción del sujeto. Sociología, 4, 59-84.

Femenías, M. L. (2003). Aproximación al pensamiento de Judith Butler. Conferencia impartida en Gijón, 5 de diciembre de 2003.

Glick, P. y Fiske, S. T. (1996). The Ambivalent Sexism Inventory: Differentiating hostile and benevolent sexism. Journal of Personality and Social Psychology, 70, 491-512.

Green, V. A.; Bigler, R. y Catherwood, D. (2004). The variability and flexibility of gendertyped toy play: a close look at children's behavioral responses to counterstereotypic models. Sex Role, 51, 371-386.

Liben, L. S.; Bigler, R. S., y Krogh, H. R. (2001). Pink and blue collar jobs: Children's judgments of job status and job aspirations in relation to sex of worker. Journal of Experimental Child Psychology, 79, 346-363.

López Pardina, T. (2012). De Simone de Beauvoir a Judith Butler: el género y el sujeto. Revista Temas. Disponible en http://roderic.uv.es/bitstream/handle/10550/46341/101107.pdf?sequence $=1$. Fecha de consulta 3/02/17.

Nhundu, T. J. (2007). Mitigating gender-typed occupational preferences of Zimbabwean primary school Children: The use of biographical sketches, portrayals of female role, models. Sex Roles, 56, 639-649.

O' Brien, M. y Huston, A. C. (1985). Development of sex-typed play behavior in toddlers. Developmental Psychology, 21(5), 866-871.

Ochoa, D.; Parra, M. y García, C. T. (2006). Los cuentos infantiles: niñas sumisas que esperan un príncipe y niños aventureros, malvados y violentos. Revista Venezolana de Estudios de la Mujer v. 11(27), Caracas. Disponible en http://www.scielo.org.ve/scielo.php?script=sci_arttext\&pid=S1316-

37012006000200009\&lng=es\&nrm=iso\&tlng=es. Fecha de consulta 3/02/17.

Rich, Adrienne (1985). "Heterosexualidad obligatoria y existencia lesbiana". Revista "Nosotras que nos queremos tanto", 3, Colectivo de Lesbianas Feministas de Madrid. 